\title{
Studies on Chitin. I. Acetylation of Chitin*
}

\author{
Norio Nishi, Junzo NoguchI, Seiichi TokuRa, and Hiroyuki Shiota \\ Department of Polymer Science, Faculty of Science, Hokkaido \\ University, Sapporo 060, Japan
}

(Received February 8, 1978)

\begin{abstract}
Chitin was converted into diacetylchitin and also into various kinds of acetylchitins. A fully acetylated chitin was prepared by the acetylation of chitin in acetic anhydride-methanesulfonic acid mixture at $0^{\circ} \mathrm{C}$ overnight, or in acetic anhydride-perchloric acid mixture at $0^{\circ} \mathrm{C}$ for $3 \mathrm{~h}$. Variously acetylated chitins were prepared by similar procedures applying a calculated amount of acetic anhydride in glacial acetic acid. The reaction of alkaline chitin with acetic anhydride gave 0.3 acetylchitin $(0.3 \mathrm{~mol}$ of $-\mathrm{OH}$ groups are acetylated per one $\mathrm{N}$-acetylglucosamine residue), and heating this with anhydrous sodium acetate in acetic anhydride produced $c a 1.1$ acetylchitin. However, it was difficult to further improve the degree of acetylation by this alkaline method. The acetylation of chitin resulted in an increase of solubility in formic acid, and diacetylchitin was easily soluble even in $85-\%$ aqueous formic acid. The analytical data showed that the chitin residue exists as a stable hemihydrate unless it is completely acetylated. Infrared absorption spectra for chitin and acetylchitins were also investigated.
\end{abstract}

KEY WORDS Chitin / Acetylchitin / Acetylation / Methanesulfonic Acid / Perchloric Acid / Acetic Anhydride / Solubility / Formic Acid / Infrared Absorption Spectra /

Chitin is a polysaccharide having a similar chemical structure to cellulose and is widely distributed in nature, e.g., in crustaceans, insects, mushrooms and in the cell walls of bacteria. Chitin is composed of $N$-acetyl-D-glucosamine residue by a $1,4-\beta$-bond structure and can be regarded as an analogue of cellulose, with an aminoacetyl group instead of the C-2 hydroxyl group. However, the chemical properties of chitin are completely different from those of cellulose in spite of their similar structures. In particular, chitin is very resistant to chemical reagents compared to cellulose. This difference between chitin and cellulose in their chemical properties is due to the strong micelle structure of the aminoacetyl group in the chitin molecule. For this reason, research on the solvents or chemical reagents suitable for chitin has not developed very far and chitin is not yet regarded as a useful resource compared to other polysaccharides such as cellulose or starch.

* Presented in part at the First International Conference on Chitin/Chitosan, 1977, Boston, U.S.A. and the Annual Meeting of the Society of Fiber Science and Technology Japan, 1977, Tokyo, Japan.
Many kinds of cellulose derivative have been reported and widely utilized especially for their esters and ethers. With regard to acetylcellulose ${ }^{1,2}$ in particular, the degree of acetylation can be easily controlled and it can be used for fibers, plastics, films and paints. In particular, its fiber has been put to practical use over the years as "acetate fiber".

Of the chitin derivatives, nitrate, ${ }^{3}$ sulfate, ${ }^{4}$ methyl ether, ${ }^{5}$ hydroxyethyl ether, ${ }^{6,7}$ carboxymethyl ether, ${ }^{8-11}$ and acetate ${ }^{12}$ have been reported. But, generally speaking, extreme reaction conditions are necessary to obtain the desired products, and so their general utilization is far off. The procedure for using hydrogen chloride in acetic anhydride was reported ${ }^{12}$ also for the acetylation of chitin, but it takes considerable time to acetylate chitin completely by this method and the decomposition of chitin may be unavoidable during the long reaction time.

In this paper, preparative methods for variously acetylated chitins were investigated in detail as a typical chitin derivative, and easier methods for acetylation are reported. 


\section{EXPERIMENTAL}

The elemental analyses for chitin and acetylchitins were carried out by means of a Yanagimoto CHN Corder, Model MT-2, and Coleman Nitrogen Analyzer, Model 29. Thermal analyses were carried out with Meiho Thermo Analyzer MP-2. The infrared absorption spectra were measured with a Hitachi Grating Infrared Spectrophotometer, EPI-G2, by the $\mathrm{KBr}$ pellet method.

\section{Chitin}

Powdered chitin of crab shell (Alaska King Crab) was obtained from Nippon Suisan Co. Ltd. It was found by elemental analysis that chitin is tightly bound to half a mole of water per each $\mathrm{N}$-acetylglucosamine residue. Anal. Found: C, 44.96; $\mathrm{H}, 6.50 ; \mathrm{N}, 6.57$. Calcd for $\mathrm{C}_{8} \mathrm{H}_{13} \mathrm{NO}_{5}$. $1 / 2 \mathrm{H}_{2} \mathrm{O}: \mathrm{C}, 45.28 ; \mathrm{H}, 6.60 ; \mathrm{N}, 6.60$.

\section{Acetylation Procedures to Use Methanesulfonic Acid as a Catalyst}

(a) Variously Acetylated Chitins. Chitin powder $(5 \mathrm{~g})$ was added to an ice-cold mixture of methanesulfonic acid $(20 \mathrm{ml})$, glacial acetic acid $(30 \mathrm{ml})$ and a calculated amount of acetic anhydride. The mixture was stirred for $4 \mathrm{~h}$ at $0^{\circ} \mathrm{C}$ and then kept overnight at $0^{\circ} \mathrm{C}$. The reaction mixture was poured into ice water to precipitate acetylchitin. The precipitate was filtered and washed with water. The product was resuspended in distilled water, the mixture neutralized to $\mathrm{pH} 7$ with ammonium hydroxide and boiled for $1 \mathrm{~h}$. Acetylchitin was collected by filtration, washed with distilled water and dried in vacuo. The amount of acetic anhydride used, the degree of acetylation and the results of elemental analyses are shown in Table I. (b) Diacetylchitin. Chitin powder $(50 \mathrm{~g})$ was added to a mixture of methanesulfonic acid $(200 \mathrm{~m} l)$ and acetic anhydride $(300 \mathrm{~m} l)$ with srirring by vibrating mixer at $0^{\circ} \mathrm{C}$. The reaction mixture became a viscous and clear solution after stirring for $3 \mathrm{~h}$ at $0^{\circ} \mathrm{C}$, and was kept at $0^{\circ} \mathrm{C}$ overnight. The product was precipitated by the addition of ice water and the precipitate was treated by the same procedures as described in (a); yield $61 \mathrm{~g}$ $(90 \%)$. Anal. Found: C, 49.46; H, 6.00; N, 4.72. Calcd for $\mathrm{C}_{8} \mathrm{H}_{11} \mathrm{NO}_{3}\left(\mathrm{OCOCH}_{3}\right)_{2}: \mathrm{C}, 50.17 ; \mathrm{H}$, $5.92 ; \mathrm{N}, 4.88$.

\section{Acetylation Procedures Using Perchloric Acid as a Catalyst}

(a) Preparation of Perchloric Acid Solution in Glacial Acetic Acid. Ice-cold 70-\% aqueous perchloric acid $(10 \mathrm{~m} l)$ was added dropwise to acetic anhydride $(26.2 \mathrm{ml})$ with stirring at $0^{\circ} \mathrm{C}$ and the mixture was kept at $0^{\circ} \mathrm{C}$ overnight.

(b) Variously Acetylated Chitins. A calculated amount of acetic anhydride was added to a mixture of the above mentioned perchloric acid solution $(3.3 \mathrm{ml})$ and glacial acetic acid $(45 \mathrm{ml})$ at $0^{\circ} \mathrm{C}$. Chitin powder $(5 \mathrm{~g})$ was added and the reaction mixture was stirred for $5 \mathrm{~h}$ at $0^{\circ} \mathrm{C}$. The mixture was poured into ice water, the precipitate was collected by filtration and washed with water. The product was resuspended in distilled water, the mixture was neutralized to $\mathrm{pH} 7$ with ammonium hydroxide and boiled for $1 \mathrm{~h}$. The product was collected by filtration, washed with water and then treated with boiling ethanol for $90 \mathrm{~min}$. The acetylchitin was filtered, washed with ethanol and dried in vacuo. Variously acetylated chitins were prepared by this method. The amount of acetic anhydride used, the degree of acetylation and the

Table I. The relationship between the degree of acetylation and the acetic anhydride added (methanesulfonic acid method)

\begin{tabular}{|c|c|c|c|c|c|c|c|}
\hline \multirow{2}{*}{$\begin{array}{l}\text { Molar } \\
\text { ratio }^{\mathrm{a}}\end{array}$} & \multirow{2}{*}{$\begin{array}{l}\text { Degree of } \\
\text { acetylation }^{b}\end{array}$} & \multicolumn{3}{|c|}{ Found, \% } & \multicolumn{3}{|c|}{ Calcd values, \% } \\
\hline & & $\mathrm{C}$ & $\mathrm{H}$ & $\mathrm{N}$ & $\mathrm{C}$ & $\mathbf{H}$ & $\mathbf{N}$ \\
\hline 1.0 & 1.0 & 47.30 & 6.18 & 5.49 & 47.24 & 6.30 & 5.51 \\
\hline 1.6 & 1.1 & 47.78 & 6.41 & 5.73 & 47.57 & 6.25 & 5.44 \\
\hline 2.6 & 1.4 & 48.57 & 6.18 & 5.39 & 48.50 & 6.14 & 5.23 \\
\hline 3.0 & 1.6 & 49.00 & 6.10 & 5.15 & 49.09 & 6.06 & 5.11 \\
\hline 3.5 & 1.7 & 49.16 & 6.14 & 5.11 & 49.36 & 6.02 & 5.05 \\
\hline
\end{tabular}

a Equivalent moles of acetic anhydride/ $N$-acetylglucosamine residue.

b Acetylated groups $/ N$-acetylglucosamine residue. 


\section{Studies on Chitin. I.}

Table II. The relationship between the degree of acetylation and the acetic anhydride added (perchloric acid method)

\begin{tabular}{cccc}
\hline & \multirow{2}{*}{$\begin{array}{c}\text { Molar } \\
\text { ratio }^{\mathrm{a}}\end{array}$} & $\begin{array}{c}\text { Degree of } \\
\text { acetylation }^{\mathrm{b}}\end{array}$ & \multicolumn{2}{c}{ N content $(\%)$} & Found & $\begin{array}{c}\text { Calcd } \\
\text { values }\end{array}$ \\
\hline 0.8 & 0.4 & 6.13 & 6.12 \\
1.6 & 0.6 & 5.96 & 5.90 \\
2.6 & 1.2 & 5.37 & 5.37 \\
3.7 & 2.0 & 4.67 & 4.88 \\
\hline
\end{tabular}

a Equivalent moles of acetic anhydride/ $N$-acetylglucosamine residue.

b Acetylated groups/ $\mathrm{N}$-acetylglucosamine residue.

results of nitrogen analyses are shown in Table II.

(c) Diacetylchitin. To the mixture of acetic anhydride $(620 \mathrm{ml})$ and perchloric acid in glacial acetic acid $(33 \mathrm{ml})$, was added chitin powder $(50 \mathrm{~g})$ at $0^{\circ} \mathrm{C}$ and the mixture was stirred for $3 \mathrm{~h}$ at $0^{\circ} \mathrm{C}$. The mixture was poured into a large amount of ice water and the product worked up by the same procedures as described in (b); yield $65 \mathrm{~g}(96 \%)$. Anal. Found: C, 50.00; H, 6.14; N, 4.76. Calcd for $\mathrm{C}_{8} \mathrm{H}_{11} \mathrm{NO}_{3}\left(\mathrm{OCOCH}_{3}\right)_{2}: \mathrm{C}, 50.17 ; \mathrm{H}, 5.92 ; \mathrm{N}$, 4.88.

\section{Acetylation Procedures Using Hydrogen Chloride as a Catalyst}

Chitin was acetylated by the method of Schorigin and Hait. ${ }^{12}$ Chitin powder (10 g) was suspended in acetic anhydride, the mixture was saturated with hydrogen chloride and kept for 10 days at $0^{\circ} \mathrm{C}$. The reaction mixture was added to ice water. The precipitate was collected, washed with water and then washed with ethanol. Nearly $1.6 \mathrm{~mol}$ of $\mathrm{OH}$ groups per each $N$-acetylglucosamine residue were found to be acetylated by elemental analysis; yield $10.9 \mathrm{~g}(85 \%)$. Anal. Found: C. 48.48; H, 6.07; $\mathrm{N}$, 5.18. Calcd for $\left[\mathrm{C}_{8} \mathrm{H}_{11} \mathrm{NO}_{3}\left(\mathrm{OCOCH}_{3}\right)_{2}\right]_{0.6}$ $\left[\mathrm{C}_{8} \mathrm{H}_{11} \mathrm{NO}_{3}(\mathrm{OH})\left(\mathrm{OCOCH}_{3}\right) \cdot 1 / 2 \mathrm{H}_{2} \mathrm{O}_{0.4}: \mathrm{C}, 49.09\right.$; $\mathrm{H}, 6.06$; N, 5.11 .

\section{Acetylation Procedures Using Alkaline Methods}

(a) Preparation of Acetylchitin from Alkaline Chitin. Alkaline chitin was prepared from chitin powder (50 g) as described previously. ${ }^{13}$ Alakaline chitin was put into a fractionating funnel, the system was evacuated and then frozen at $-20^{\circ} \mathrm{C}$ overnight. Acetic anhydride $(100 \mathrm{ml})$ was added slowly with the aid of internal reduced pressure and shaken vigorously on cooling with ice. The mixture was kept for $24 \mathrm{~h}$ at room temperature with occasional shaking. The product, precipitated with water, was collected by filtration, washed with water and dried in vacuo. It was found by elemental analysis that $0.3 \mathrm{~mol}$ of $\mathrm{OH}$ groups per $1 \mathrm{~N}$-acetylglucosamine residue were acetylated ( 0.3 acetylchitin or $15-\%$ acetylated chitin); yield $45 \mathrm{~g} \mathrm{(85 \% ).} \mathrm{Anal.} \mathrm{Found:} \mathrm{C,} \mathrm{45.93;}$ $\mathrm{H}, 6.69 ; \mathrm{N}, 6.21$. Calcd for $\left[\mathrm{C}_{8} \mathrm{H}_{11} \mathrm{NO}_{3}(\mathrm{OH})_{2}\right.$. $\left.1 / 2 \mathrm{H}_{2} \mathrm{O}\right]_{0.7}\left[\mathrm{C}_{8} \mathrm{H}_{11} \mathrm{NO}_{3}(\mathrm{OH})\left(\mathrm{OCOCH}_{3}\right) \cdot 1 / 2 \mathrm{H}_{2} \mathrm{O}_{0.3}\right.$; C, $45.95 ; \mathrm{H}, 6.50 ; \mathrm{N}, 6.23$.

(b) Preparation of Acetylchitin from Chitin Viscose. To a chitin viscose solution prepared from chitin $(2.5 \mathrm{~g})$ as described previously, ${ }^{13}$ icecold acetic anhydride $(6.3 \mathrm{ml})$ was added and the mixture was shaken at $0^{\circ} \mathrm{C}$. After standing overnight at room temperature, the product was precipitated with cold water, followed by filtering, washing with water and then drying in vacuo. Nearly $0.3 \mathrm{~mol}$ of $\mathrm{OH}$ groups per $1 \mathrm{~N}$-acetylglucosamine residue were found to be acetylated from the elemental analysis similarly to the result described in (a); yield $2.2 \mathrm{~g}(83 \%)$. Anal. Found: $\mathrm{C}, 45.74 ; \mathrm{H}, 6.59 ; \mathrm{N}, 6.06$. Calcd for $\left[\mathrm{C}_{8} \mathrm{H}_{11} \mathrm{NO}_{3}{ }^{-}\right.$ $\left.(\mathrm{OH})_{2} \cdot 1 / 2 \mathrm{H}_{2} \mathrm{O}\right]_{0.7}\left[\mathrm{C}_{8} \mathrm{H}_{11} \mathrm{NO}_{3}(\mathrm{OH})\left(\mathrm{OCOCH}_{3}\right) \cdot\right.$ $1 / 2 \mathrm{H}_{2} \mathrm{O}_{0.3}$ : C, 45.95; H, 6.50; N, 6.23.

(c) Preparation of 1.1 Acetylchitin from 0.3 Acetylchitin. 0.3 Acetylchitin (15-\% acetylated chitin) (2.0 g) prepared by the procedures described in (b), anhydrous sodium acetate $(0.84 \mathrm{~g})$ and acetic anhydride $(8.1 \mathrm{ml})$ were mixed and heated at $96^{\circ} \mathrm{C}$ for $24 \mathrm{~h}$ under reduced pressure in a sealedbottle. The product was precipitated with water, filtered, washed with water and then dried in vacuo. It was found from the elemental analysis that $1.1 \mathrm{~mol}$ of $\mathrm{OH}$ groups per $1 \mathrm{~N}$-acetylglucosamine residue were acetylated (1.1 acetylchitin or $55-\%$ acetylated chitin); yield $1.9 \mathrm{~g} \mathrm{(83 \% ).} \mathrm{Anal.}$ Found: C, 47.64; H, 6.32; N, 5.78. Calcd for $\left[\mathrm{C}_{8} \mathrm{H}_{11} \mathrm{NO}_{3}\left(\mathrm{OCOCH}_{3}\right)_{2}\right]_{0.1}\left[\mathrm{C}_{8} \mathrm{H}_{11} \mathrm{NO}_{3}(\mathrm{OH})(\mathrm{OCO}-\right.$ $\left.\left.\mathrm{CH}_{3}\right) \cdot 1 / 2 \mathrm{H}_{2} \mathrm{O}\right]_{0.9}: \mathrm{C}, 47.57 ; \mathrm{H}, 6.25 ; \mathrm{N}, 5.44$.

\section{RESULTS AND DISCUSSION}

\section{Acetylation of Chitin with Acid Catalyst}

In the case of cellulose, a completely acetylated derivative, triacetylcellulose, is soluble in ordinary solvents such as methylene chloride, acetic acid, etc. Thus it is not particularly difficult to acetylate 
cellulose because, if such solvents are employed, the reaction mixture for acetylation becomes homogeneous at least at the end of the reaction. But, in the case of chitin, it is not so easy to acetylate it completely since it has a strong micelle structure and threfore even completely acetylated chitin, diacetylchitin, is not soluble in such solvents.

In spite of these difficulties, methanesulfonic acid was found to be a suitable solvent and catalyst for the homogeneous acetylation reaction. The temperature for the reaction was set at $0^{\circ} \mathrm{C}$, the lowest temperature at which the reaction mixture would not freeze, to prevent decomposition of the chitin by methanesulfonic acid. The acetylation reactions in the mixture of acetic anhydride and methanesulfonic acid in various ratios were investigated. Consequently, it was found that, when a mixture of four parts of methanesulfonic acid ( $\mathrm{v} / \mathrm{w})$ and six parts of acetic anhydride $(\mathrm{v} / \mathrm{w})$ for one part of chitin powder was employed, a completely clear and homogeneous reaction mixture was obtained in only $1-2 \mathrm{~h}$. When a smaller amount of methanesulfonic acid is employed, it is hard to obtain $100-\%$ acetylated chitin owing to the heterogeneity of the reaction mixture.

Variously acetylated chitins were also prepared in a mixture of four parts of methanesulfonic acid $(\mathrm{v} / \mathrm{w})$ and six parts of glacial acetic acid $(\mathrm{v} / \mathrm{w})$ using a calculated amount of acetic anhydride, as in the case of diacetylchitin preparation. Acetylchitin at various degrees of acetylation can be easily prepared by this method, considering the relationship between the degree of acetylation and the amount of acetic anhydirde added as is shown in Table I. However, in this case, a clear and homogeneous reaction mixture cannot be obtained. When perchloric acid is employed as a catalyst for the acetylation reaction in acetic anhydride, diacetylchitin can easily be obtained in a short time in spite of the heterogeneous reaction mixture. This can be explained by the high acidity of perchloric acid. And also, in this case, various kinds of acetylchitin can be prepared by employing a calculated amount of acetic anhydirde in glacial acetic acid as in the case of the acetylation reaction in methanesulfonic acid. The relationship between the degree of acetylation and the amount of acetic anhydride employed is shown in Table II. The perchloric acid solution as a catalyst for this method has to be anhydrous to prevent the hydrolysis of the chitin. Hence, perchloric acid solution in glacial acetic acid was prepared before use by the method described in the experimental section.

As an acetylation procedure using other acid catalysts, Schorigin and $\mathrm{Hait}^{12}$ reported that chitin could be converted to variously acetylated chitins by saturation of dry hydrogen chloride in acetic anhydride. However, according to their paper, it takes ca. $120 \mathrm{~h}$ at $23^{\circ} \mathrm{C}$ to obtain completely acetylated chitin. We also tried this method at $0^{\circ} \mathrm{C}$ for 10 days employing a low temperature to prevent the decomposition of the chitin. Consequently, nearly $1.6 \mathrm{~mol}$ of $\mathrm{OH}$ groups per each $N$ acetylglucosamine residue were acetylated. Anyway, this is difficult and takes a long time to acetylate the chitin completely by this hydrogen chloride method. This method also has the disadvantage of poor reproducibility for the preparation of variously acetylated chitins.

\section{Acetylation of Chitin by the Alkaline Method}

When alkaline chitin is treated with acetic anhydride under reduced pressure, acetylchitin in which $0.3 \mathrm{~mol}$ of $\mathrm{OH}$ groups per each $N$-acetylglucosamine residue are acetylated $(0.3$ acetylchitin), can be reproducibly obtained. However, it is hard to raise the degree of acetylation further by treating with a larger excess of acetic anhydride. The reaction of chitin viscose with acetic anhydride also gives acetylchitin with the same degree of acetylation as the above reaction. Well dried 0.3 acetylchitin thus obtained can be converted to 1.1 acetylchitin by treating it again with acetic anhydride and anhydrous sodium acetate at $95^{\circ} \mathrm{C}$ for $24 \mathrm{~h}$. This reaction needs a higher reaction temperature and is not apt to proceed at a low temperature such as $0^{\circ} \mathrm{C}$ or $20^{\circ} \mathrm{C}$. However, the longer heating time at temperatures over $100^{\circ} \mathrm{C}$ causes colorization or decomposition of the chitin. Thus, it is very hard to acetylate more than $1.1 \mathrm{~mol}$ of hydroxyl groups per each residue by this method. Although this sodium acetate method has been used for the acetylation of cellulose, it is not very suitable for the acetylation reaction of chitin. When this anhydrous sodium acetate method for the acetylation reaction is applied to chitin itself, the reaction scarcely proceeds at all. This fact can be interpreted by supposing that whereas chitin has the strong micelle structure, the 0.3 acetylchitin does not. In the case of 0.3 acetyl- 
chitin, the micelle structure seems to be broken by the freezing procedure of alkaline chitin during its preparation, and as a result, it might come to have a better reactivity. Generally, chitin seems to differ from cellulose in the respect that treatment at low temperatures increases its reactivity.

The acetylation reaction applying a basic catalyst such as pyridine or piperidine did not proceed smoothly at lower temperatures and the chitin tended to decompose with colorization at higher temperatures.

\section{Properties of Acetylchitins}

The increase of solubility toward formic acid was observed following an increase in the degree of acetylation. Among the acetylchitins, diacetylchitin showed the highest solubility toward $99-\%$ formic acid, even to $85-\%$ formic acid, independent of the catalyst. Acetylchitins prepared by the alkaline method also have high solubility in 99- $\%$ formic acid. The others were slightly less soluble in $99-\%$ formic acid. However, they could be dissolved in $99-\%$ formic acid by applying the freezing process. There are few solvents for acetylchitins except acidic solvents, such as formic acid, dichloroacetic acid and methanesulfonic acid, thus differing from acetylcellulose. A slight split of the glycoside linkage of the chitin molecule was observed during the acetylation reaction, especially in the case of diacetylchitins, by the measurement of viscosity. As the reduction of viscosity was not fatal for further investigation of acetylchitin fibers, only the reaction time and temperature were regulated, as mentioned above, to prevent serious decrease in the molecular weight of chitin.

\section{Infrared Absorption Spectra of Chitin and Acetyl- chitins}

Infrared absorption spectra of chitin and variously acetylated chitins are shown in Figure 1. According to the infrared absorption spectrum of chitin studied by Pearson, et al., ${ }^{14}$ and by Gardner and Blackwell, ${ }^{15}$ there are two kinds of structures for chitin referred to as $\alpha$ - and $\beta$-structure. The natural-type chitin has the $\alpha$-structure and is supposed to be converted to the $\beta$-structure during a process to isolate chitin such as the procedure for removing protein or calcium. The infrared absorption spectrum of $\alpha$-type chitin has a characteristic absorption at $1660 \mathrm{~cm}^{-1}$ and that of $\beta$-type

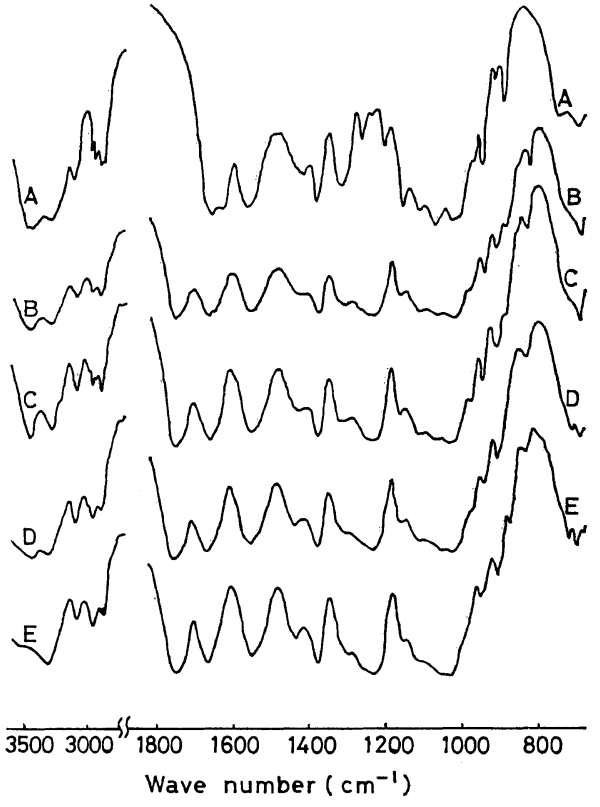

Figure 1. Infrared absorption spectra of chitin and acetylchitins: A, chitin; B, 1.1 acetylchitin; C, 1.4 acetylchitin; D, 1.7 acetylchitin; E, diacetylchitin.

chitin has two absorptions, at 1620 and $1660 \mathrm{~cm}^{-1}$. As the chitin, which we used as a starting material, has two absorptions at 1620 and $1660 \mathrm{~cm}^{-1}$, it seems to have the $\beta$-structure. On proceeding with the acetylation, the absorptions at 1750 and $1230 \mathrm{~cm}^{-1}$ which are characteristic for the ester of saturated fatty acid and for the ester of acetic acid, respectively, increased extensively, but the absorption at $3480 \mathrm{~cm}^{-1}$ due to $\mathrm{OH}$ stretching decreased noticeably. However, the absorption at $3447 \mathrm{~cm}^{-1}$ also due to the $\mathrm{OH}$ group did not decrease until after a considerable degree of acetylation. The decrease of absorption at $1013 \mathrm{~cm}^{-1}$ due to a primary alcohol is slightly prior to that at 1120 $\mathrm{cm}^{-1}$ for a secondary alcohol. Hence, the primary alcohol of C-6 position seems to be acetylated somewhat prior to the secondary alcohol of C-3 position. The absorption at $750 \mathrm{~cm}^{-1}$ due to out of plane bending of the $\mathrm{NH}$ group also disappears quickly as the acetylation proceeds. This fact, when compared with the decreasing rate of two absorptions at 3480 and $3447 \mathrm{~cm}^{-1}$ due to two hydroxyl groups, can be interpreted by supposing that the hydrogen bond of aminoacetyl group is with the C-6 hydroxyl group and the absorption due to the hydrogen bond between the other hy- 
droxyl groups appears at $3447 \mathrm{~cm}^{-1}$. The latter hydrogen bond should remain stable until a considerable degree of acetylation is attained. The absorption at $1620 \mathrm{~cm}^{-1}$ also disappears rapidly as acetylation proceeds. This seems due to adsorbed water on comparison with the results of elemental analyses described above. The acetylation process is accompanied also with a decrease in a series of absorptions at 2930, 2890, and 2878 $\mathrm{cm}^{-1}$ which seem due to $\mathrm{C}-\mathrm{H}$ stretching. Although these phenomena are considered at the present to be a result of the destruction of the micelle structure in chitin, further investigation must be done for confirmation.

\section{Compositions of Chitin and Acetylchitins}

Chitin was considered to have tightly bound water, according to elemental analysis, infrared absorption spectrum and thermal analysis. This bound water was found to be released at a temperature of over $115^{\circ} \mathrm{C}$ as a result of the thermal behavior of the chitin shown in Figure 2. Chitin contains $1 / 2 \mathrm{H}_{2} \mathrm{O}$ per each $\mathrm{N}$-acetylglucosamine residue because the result of the elemental analysis for chitin agrees with formula of $\left[\mathrm{C}_{8} \mathrm{H}_{11} \mathrm{NO}_{3}(\mathrm{OH})_{2}\right.$.

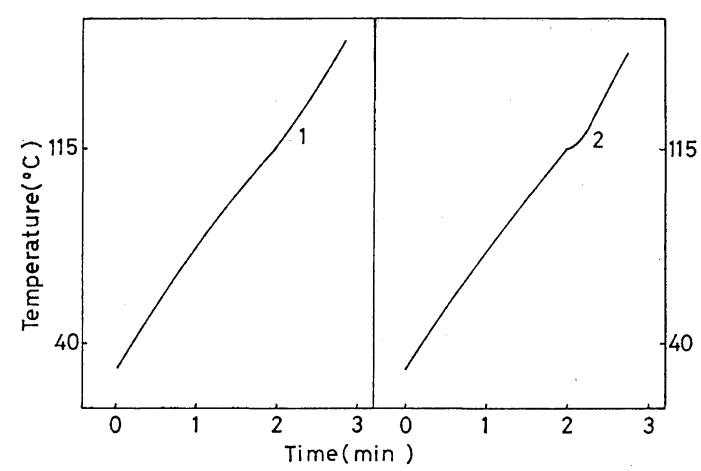

Figure 2. Thermal behaviors of chitin and diacetylchitin: 1, diacetylchitin; 2 , chitin.
$1 / 2 \mathrm{H}_{2} \mathrm{O}$ ] after drying several hours at $100^{\circ} \mathrm{C}$ in vacuo. No water is bound to completely acetylated chitin, diacetylchitin, and its composition was found to be $\left[\mathrm{C}_{8} \mathrm{H}_{11} \mathrm{NO}_{3}\left(\mathrm{OCOCH}_{3}\right)_{2}\right]$. The composition of the intermediates for acetylation agrees well with the results of the elemental analyses, assuming that the residue binds half a mole of water even in the monoacetylated residue, $\left[\mathrm{C}_{8} \mathrm{H}_{11} \mathrm{NO}_{3}\right.$ $(\mathrm{OH})\left(\mathrm{OCOCH}_{3}\right) \cdot 1 / 2 \mathrm{H}_{2} \mathrm{O}$, and there is no water bound to the diacetylated residue, $\left[\mathrm{C}_{8} \mathrm{H}_{11} \mathrm{NO}_{3}\right.$ $\left.\left(\mathrm{OCOCH}_{3}\right)_{2}\right]$.

Acknowledgement. The authors should like to express their sincere appreciation to Mitsubishi Rayon Co. Ltd., Kreha Kagaku Co. Ltd. and Nippon Suisan Co. Ltd. for their supports.

\section{REFERENCES}

1. A. Franchimont, Compt. Rend., 89, 711 (1879).

2. H. Ost, Angew. Chem., 32, 66 (1919)

3. P. Schorigin and E. Hait, Ber., 67, 1712 (1934).

4. I. B. Cushing, R. V. Davis, E. J. Kratoril, and D. W. MacCorquodare, J. Am. Chem. Soc., 76, 4590 (1954).

5. P. Schorigin and N. N. Makarowa-Semljanskaja, Ber., 68, 969 (1935).

6. R. Senju and S. Okimasu, Nogei Kagaku, 23, 432 (1949).

7. S. Okimasu and R. Senju, Nogei Kagaku, 23, 437 (1949).

8. S. Okimasu, Nogei Kagaku, 32, 547 (1957).

9. S. Okimasu, Nogei Kagaku, 32, 383 (1957).

10. S. Okimasu, Nogei Kagaku, 32, 387 (1957).

11. S. Okimasu, Nogei Kagaku, 32, 471 (1957).

12. P. Schorigin and E. Hait, Ber., 68, 971 (1935).

13. J. Noguchi, O. Wada, H. Seo, S. Tokura, and N. Nishi, Kobunshi Kagaku, 30, 338 (1973).

14. F. G. Pearson, R. H. Marchessault, and C. Y. Liang, J. Polym. Sci., 18, 101 (1960).

15. K. H. Gardner and J. Blackwell, Biopolymers, 14, 1581 (1975). 